\title{
Propriedades físico-hídricas do solo e demanda energética de haste escarificadora em Argissolo compactado
}

\author{
Marcelo Ivan Mentges(1), José Miguel Reichert(1), David Peres da Rosa(2), \\ Davi Alexandre Vieira( ${ }^{(1)}$, Vanderleia Trevisan da Rosa ${ }^{(1)}$ e Dalvan José Reinert ${ }^{(1)}$
}

\begin{abstract}
(1)Universidade Federal de Santa Maria, Centro de Ciências Rurais, Departamento de Solos, Avenida Roraima, no 1.000, CEP 97105-900 Santa Maria, RS. E-mail: marcelomentges@gmail.com, reichert@smail.ufsm.br, agronomo.davi@gmail.com, vandetrevisan@gmail.com, dalvan@smail.ufsm.br (2)Universidade do Estado de Santa Catarina, Departamento de Agronomia, Avenida Luiz Camões, no 2.090, CEP 88520-000 Lages, SC. E-mail: david.dpr@gmail.com
\end{abstract}

Resumo - O objetivo deste trabalho foi avaliar o efeito da compactação nos atributos físico-hídricos do solo e na demanda energética da haste escarificadora, além de avaliar as propriedades físico-hídricas abaixo da profundidade de trabalho da haste. O trabalho foi conduzido em Argissolo Vermelho-Amarelo de textura francoarenosa, com os seguintes tratamentos: plantio direto por 13 anos; plantio direto por 13 anos em solo escarificado; plantio direto em solo com compactação adicional; e plantio direto em solo com compactação adicional escarificado. A compactação, ao longo da profundidade escarificada, foi verificada por meio dos dados de esforço de tração associados à haste escarificadora, obtidos com auxílio de um anel octogonal ligado a um módulo de aquisição de dados. Foram determinados densidade, porosidade total, macroporosidade, microporosidade, condutividade hidráulica saturada e resistência mecânica do solo à penetração. A compactação elevou a densidade e a resistência mecânica à penetração do solo, reduziu a porosidade total e a macroporosidade, porém sem causar efeitos significativos na microporosidade. A compactação aumentou a demanda energética da haste escarificadora em $21,64 \%$, o que elevou os valores médios de esforço de tração de 5,33 para 6,35 kN. A escarificação não elevou o estado de compactação do solo abaixo da profundidade de trabalho da haste escarificadora, em solo francoarenoso.

Termos para indexação: condutividade hidráulica, esforço de tração, resistência à penetração, plantio direto.

\section{Soil physicohydric properties and chisel energy demand in a compacted Alfisol}

\begin{abstract}
The objective of this work was to evaluate the soil compaction effect on its physicohydric properties and on chisel energy demand, as well as to quantify the behavior of these properties below the chisel working depth. The experiment was carried out in a sandy loam Alfisol, with the following treatments: no-tillage for 13 years; no-tillage for 13 years and chiseling; no-tillage with additional compaction; and no-tillage with additional compaction and chiseling. Compaction along the chiseling depth was verified through data of traction effort associated to the chisel, obtained with the aid of an octagonal ring linked to a data acquisition module. Soil bulk density, total porosity, macroporosity, microporosity, hydraulic conductivity and soil resistance to mechanical penetration were also determined. Soil compaction increased both soil bulk density and resistance to mechanical penetration, reducing the total porosity and the macroporosity, without causing significant effects in microporosity. The compaction increased chisel energy demand in $21.64 \%$, increasing the mean value of traction effort from $5.33 \mathrm{kN}$ to $6.35 \mathrm{kN}$. Soil chiseling did not increase soil compaction status below the chisel working depth in the sandy loam Alfisol.
\end{abstract}

Index terms: hydraulic conductivity, traction effort, resistance to penetration, no-tillage.

\section{Introdução}

O uso do sistema de plantio direto (SPD) tem resultado em redução significativa da degradação do solo, em razão da ausência de revolvimento e da contínua deposição de resíduos vegetais em superfície. Porém, com o passar dos anos, têm sido identificadas alterações estruturais em solos cultivados sob esse sistema. Dados publicados e observações visuais indicam que solos sob SPD têm apresentado problemas de compactação subsuperficial, na camada entre 8 e $15 \mathrm{~cm}$ de profundidade (Reinert et al., 2008; Secco et al., 2009), denominada por Reichert et al. (2009) de "pé-de-plantio direto".

O tráfego de máquinas agrícolas é apontado como fator determinante na ocorrência da compactação do solo (Veiga et al., 2007). Outros fatores também são importantes, como: ausência de revolvimento (Håkansson \&

Pesq. agropec. bras., Brasília, v.45, n.3, p.315-321, mar. 2010 
Medvedev, 1995), que no SPD fica restrito à linha de semeadura e a pequenas profundidades; utilização errônea da pressão de inflação dos pneus agrícolas (Håkansson, 2005); e realização das operações agrícolas com teores inadequados de água no solo (Reichert et al., 2007; Klein et al., 2008).

Para a redução ou o alívio dos efeitos da compactação, a escarificação esporádica do solo tem sido uma alternativa viável (Camara \& Klein, 2005; Rosa et al., 2008). Essa técnica de manejo ocasiona redução na densidade e aumento na macroporosidade do solo (Klein et al., 2008). Melhorias nas propriedades físico-hídricas e mecânicas também são observadas em solos escarificados, como aumento na infiltração e na condutividade hidráulica do solo saturado (Camara \& Klein, 2005), bem como a redução da resistência à penetração (Collares et al., 2008). Além disso, Rosa (2007) e Rosa et al. (2008) observaram redução nos esforços demandados pela haste sulcadora, em um Latossolo Vermelho distrófico e em um Argissolo Vermelho distrófico arênico, respectivamente.

A ação da ponteira dos escarificadores pode, no entanto, causar compactação abaixo de sua profundidade de trabalho e formar o chamado pé-de-arado que, a depender do grau de adensamento, pode impedir o aprofundamento do sistema radicular e diminuir a infiltração de água no solo (Rosa, 2007). O pé-de-arado é facilmente encontrado em solos cultivados no sistema convencional; no entanto, seu estudo em solos cultivados sob SPD escarificados é restrito (Rosa, 2007), apesar de sua grande importância para a conservação do solo e da água em áreas com elevado grau de compactação.

Este trabalho teve por objetivo avaliar o efeito da compactação nos atributos físico-hídricos do solo e na demanda energética da haste escarificadora, além de avaliar as propriedades físico-hídricas abaixo da profundidade de trabalho da haste escarificadora.

\section{Material e Métodos}

Este trabalho foi realizado na área experimental do Departamento de Solos, da Universidade Federal de Santa Maria, na região fisiográfica da Depressão Central do

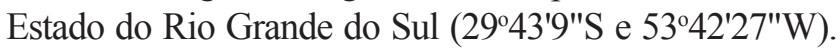
O clima da região é subtropical úmido, classificado como Cfa (Köppen), sem estiagem (Moreno, 1961). O solo é classificado como Argissolo Vermelho-Amarelo distrófico típico (Santos et al., 2006), de textura francoarenosa (Tabela 1).

O delineamento experimental utilizado foi o de blocos ao acaso, com parcelas subdivididas, com três repetições para cada tratamento. Nas parcelas principais, foram alocados os tratamentos com plantio direto por 13 anos (PD) e plantio direto com compactação adicional (CA). Nas subparcelas, o segundo fator de variação (escarificação e sem escarificação) foi casualizado.

A compactação adicional foi realizada no dia 22 de junho de 2007, com uso de uma pá carregadora, marca Case, modelo W18 (Case IH, Sorocaba, São Paulo, Brasil), com massa total de $8,531 \mathrm{Mg}$. A fim de aumentar a massa no eixo frontal, a concha da pá carregadora foi preenchida com solo, o que garantiu massa total de aproximadamente $10 \mathrm{Mg}$. Os pneus eram Firestone 14.00-24 (Bridgestone Firestone do Brasil Comércio e Indústria Ltda, Santo André, São Paulo, Brasil), desgastados pelo uso, o que evitou o cisalhamento superficial do solo. A pressão de inflação dos pneus foi de $276 \mathrm{kPa}$, o que gerou pressão de contato pneu/solo de $260,7 \mathrm{kPa}$. Foram executadas duas passadas com a pá carregadora a $1 \mathrm{~km}$ porhora, o que resultou em intensidade de tráfego de $24,67 \mathrm{Mg} \mathrm{km}^{-1} \mathrm{ha}^{-1}$. A compactação foi realizada de modo que os pneus comprimissem áreas paralelas entre si, tendo sido executadas passadas sobrepostas às anteriores, para que toda a área do tratamento CA fosse igualmente trafegada. No momento da compactação, a área encontrava-se coberta com azevém (Lolium multiflorum Lam.), com massa de matéria seca de $1,43 \mathrm{Mg} \mathrm{ha}^{-1}$. O teor de água no solo no momento da compactação, os limites de liquidez

Tabela 1. Composição granulométrica, densidade de partículas (Dp), umidade gravimétrica (Ug), limite de liquidez(LL), limite de plasticidade (LP) e índice de plasticidade (IP) do Argissolo Vermelho-Amarelo no dia da realização da compactação.

\begin{tabular}{|c|c|c|c|c|c|c|c|c|}
\hline Camada & Areia & Silte & Argila & $\mathrm{Dp}$ & $\mathrm{Ug}$ & LL & LP & IP \\
\hline & & & 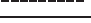 & & & & & - \\
\hline $0,0-0,1$ & 612 & 216 & 172 & 2,52 & 0,14 & 0,20 & 0,17 & 0,03 \\
\hline $0,1-0,2$ & 592 & 215 & 193 & 2,57 & 0,16 & 0,20 & 0,16 & 0,04 \\
\hline $0,2-0,3$ & 585 & 223 & 192 & 2,55 & 0,15 & 0,20 & 0,16 & 0,04 \\
\hline $0,3-0,4$ & 580 & 225 & 195 & 2,55 & 0,15 & 0,20 & 0,18 & 0,02 \\
\hline
\end{tabular}

Pesq. agropec. bras., Brasília, v.45, n.3, p.315-321, mar. 2010 
e plasticidade e o índice de plasticidade estão descritos na Tabela 1.

A avaliação do efeito da compactação no solo foi realizada pela coleta das informações sobre a demanda energética da haste escarificadora e propriedades físico-hídricas nas camadas $0-0,1 \mathrm{~m}$ e 0,1-0,2 m, nos tratamentos PD e CA. Essas informações não foram coletadas nas subparcelas (escarificado e não escarificado) em razão do curto período decorrido do revolvimento do solo pelo escarificador (1 mês). Contudo, para avaliar se a ponteira da haste do escarificador gera compactação nas camadas subsuperficiais, as propriedades físico-hídricas foram avaliadas nas camadas de 0,2-0,3 m e 0,3$0,4 \mathrm{~m}$, tanto nas parcelas como nas subparcelas. Essas amostragens foram realizadas aproximadamente um mês após a compactação.

Os esforços foram obtidos com auxílio de um anel octogonal ligado a um módulo de aquisição de dados. A profundidade teórica de trabalho foi de $0,2 \mathrm{~m}$, tendo sido o anel configurado para uma taxa de aquisição de 20 amostras por segundo. No momento da operação, o solo encontrava-se com teor de água de $0,155 \mathrm{~kg} \mathrm{~kg}^{-1}$.

Para determinar a densidade, porosidade total, macroporosidade e microporosidade do solo, foram coletadas amostras com estrutura preservada, com cilindros de aço inoxidável de $0,06 \mathrm{~m}$ de diâmetro e $0,03 \mathrm{~m}$ de altura. Tais parâmetros foram determinados segundo Claessen (1997). A condutividade hidráulica do solo saturado foi determinada por permeâmetro de carga variável, descrito por Gubiani et al. (2008). Foram coletadas, também, amostras com estrutura deformada para se determinar a granulometria, os limites de liquidez e plasticidade, o índice de plasticidade, o estado de consistência do solo (Claessen, 1997) e a densidade de partículas (Gubiani et al., 2006). As determinações citadas acima foram avaliadas nas seguintes camadas: $0-0,1,0,1-0,2,0,2-0,3$ e $0,3-0,4 \mathrm{~m}$.

A compactação foi verificada, ainda, por meio da resistência mecânica do solo à penetração, medida até $0,4 \mathrm{~m}$ de profundidade. Para tal determinação, foi usado um penetrômetro digital, Remik CP20 Ultrasonic Cone Penetrometer (RFM Australia Pty Ltd, Toowoomba, Austrália), com armazenamento eletrônico dos dados regulado para aquisição de dados a cada $0,015 \mathrm{~m}$ de profundidade, e equipado com ponta cônica com ângulo de penetração de $30^{\circ}$.
Foram realizadas amostragens na área escarificada, nas camadas de $0,2-0,3$ e $0,3-0,4 \mathrm{~m}$, a fim de se avaliar o efeito da haste escarificadora sobre as propriedades fisico-hídricas do solo abaixo da profundidade de trabalho. Nessas camadas, determinações de densidade, porosidade, macroporosidade, microporosidade e condutividade hidráulica do solo saturado foram realizadas conforme a metodologia descrita anteriormente.

$\mathrm{O}$ efeito dos fatores principais e de suas interações foram avaliados pela análise de variância a $5 \%$ de probabilidade. Quando o teste $\mathrm{F}$ foi significativo, as médias foram comparadas pelo teste da diferença mínima significativa (DMS), a 5\% de probabilidade, com uso do Sisvar (Ferreira, 2008).

\section{Resultados e Discussão}

No que se refere à densidade e à porosidade do solo, não houve interação entre as profundidade avaliadas e os tratamentos utilizados, tendo ocorrido diferenças significativas apenas entre os fatores principais (Tabela 2). A compactação adicional elevou os valores de densidade do solo em relação ao PD, mas mesmo em CA ela permaneceu abaixo de $1,74 \mathrm{Mg} \mathrm{m}^{-3}$, densidade considerada como crítica porReichertetal.(2009), para solos de textura francoarenosa. Secco et al. (2009) também observaram aumento na densidade com o aumento do grau de compactação, em dois Latossolos Vermelhos de textura argilosa.

Os maiores valores de densidade do solo foram observados nas camadas $0,0-0,1$ e $0,1-0,2 \mathrm{~m}$ que, no entanto, diferiram significativamente apenas dos observados na profundidade 0,3-0,4 m (Tabela 2). Essa elevação mostra que as cargas aplicadas ao solo por máquinas agrícolas são mais acentuadas nas camadas superficiais do solo. Similarmente, em Argissolo Vermelho de textura francoarenosa, Reinert et al. (2008) observaram incremento da densidade na camada de 0,05 a $0,30 \mathrm{~m}$. Esses autores relataram que a ausência de valores elevados de densidade do solo, na camada superficial, ocorre em razão da maior densidade de raízes, maior teor de matéria orgânica, ciclos de umedecimento e secagem e do revolvimento parcial no momento da semeadura. Entretanto, essas condições devem ter tido pouco efeito no presente estudo, pelo fato de que a amostragem foi realizada um mês após o tráfego da pá carregadora e, também, em consequência de que a área permaneceu sem cultivo nesse intervalo de tempo.

A compactação adicional reduziu a porosidade total e a macroporosidade, não tendo sido significativas as 
diferenças de microporosidade (Tabela 2). Os menores valores de porosidade total e macroporosidade foram observados na camada de $0,1-0,2 \mathrm{~m}$. Amacroporosidade, no entanto, não diferiu estatisticamente da observada na camada inicial. Esses resultados confirmam a presença de uma camada superficial mais compactada que, de acordo com Reichert et al. (2007), é considerada comum em solos sob plantio direto. A maior microporosidade foi observada na camada de $0,0-0,1 \mathrm{~m}$, que diferiu estatisticamente da camada de 0,3-0,4 m. Esses resultados assemelham-se aos obtidos por Streck et al. (2004), em Argissolo Vermelho-Amarelo distrófico arênico, que, com emprego de compactação por uma máquina com $10 \mathrm{Mg}$ de peso, observaram redução da

Tabela 2. Densidade do solo, porosidade total, microporosidade, macroporosidade e condutividade hidráulica do solo saturado em Argissolo Vermelho-Amarelo sob plantio direto, com ou sem compactação adicional ${ }^{(1)}$.

\begin{tabular}{|c|c|c|c|}
\hline Camada (m) & Plantio direto & Compactação adicional & Média \\
\hline & \multicolumn{3}{|c|}{ Densidade do solo $\left(\mathrm{Mg} \mathrm{m}^{-3}\right)$} \\
\hline $0,0-0,1$ & 1,55 & 1,71 & $1,63 \mathrm{a}$ \\
\hline $0,1-0,2$ & 1,59 & 1,67 & $1,63 \mathrm{a}$ \\
\hline $0,2-0,3$ & 1,48 & 1,63 & $1,55 \mathrm{ab}$ \\
\hline $0,3-0,4$ & 1,46 & 1,56 & $1,51 \mathrm{~b}$ \\
\hline Média & $1,52 \mathrm{~B}$ & $1,64 \mathrm{~A}$ & - \\
\hline \multirow[t]{2}{*}{ CV $(\%)$} & \multicolumn{2}{|r|}{3,95} & \\
\hline & \multicolumn{3}{|c|}{ Porosidade total $\left(\mathrm{m}^{3} \mathrm{~m}^{-3}\right)$} \\
\hline $0,0-0,1$ & 0,380 & 0,354 & $0,367 \mathrm{a}$ \\
\hline $0,1-0,2$ & 0,339 & 0,341 & $0,340 \mathrm{~b}$ \\
\hline $0,2-0,3$ & 0,382 & 0,347 & $0,364 \mathrm{a}$ \\
\hline $0,3-0,4$ & 0,383 & 0,369 & $0,376 \mathrm{a}$ \\
\hline Média & $0,371 \mathrm{~A}$ & $0,353 \mathrm{~B}$ & - \\
\hline \multirow[t]{2}{*}{ CV $(\%)$} & \multicolumn{2}{|r|}{5,09} & \\
\hline & \multicolumn{3}{|c|}{ Microporosidade $\left(\mathrm{m}^{3} \mathrm{~m}^{-3}\right)$} \\
\hline $0,0-0,1$ & 0,308 & 0,302 & $0,305 \mathrm{a}$ \\
\hline $0,1-0,2$ & 0,277 & 0,281 & $0,279 a \mathrm{ab}$ \\
\hline $0,2-0,3$ & 0,289 & 0,276 & $0,282 \mathrm{ab}$ \\
\hline $0,3-0,4$ & 0,277 & 0,276 & $0,276 \mathrm{~b}$ \\
\hline Média & $0,288 \mathrm{~A}$ & $0,284 \mathrm{~A}$ & - \\
\hline \multirow[t]{2}{*}{$\mathrm{CV}(\%)$} & \multicolumn{2}{|r|}{8,00} & \\
\hline & \multicolumn{3}{|c|}{ Macroporosidade $\left(\mathrm{m}^{3} \mathrm{~m}^{-3}\right)$} \\
\hline $0,0-0,1$ & 0,072 & 0,052 & $0,062 \mathrm{c}$ \\
\hline $0,1-0,2$ & 0,063 & 0,060 & $0,061 \mathrm{c}$ \\
\hline $0,2-0,3$ & 0,093 & 0,071 & $0,082 b$ \\
\hline $0,3-0,4$ & 0,106 & 0,093 & $0,100 \mathrm{a}$ \\
\hline Média & $0,083 \mathrm{~A}$ & $0,078 \mathrm{~B}$ & - \\
\hline \multirow[t]{2}{*}{ CV (\%) } & \multicolumn{2}{|r|}{18,09} & \\
\hline & \multicolumn{3}{|c|}{ Condutividade hidráulica saturada $\left(\mathrm{mm} \mathrm{h}^{-1}\right)$} \\
\hline $0,0-0,1$ & 111,7 & 166,5 & $139,1 \mathrm{a}$ \\
\hline $0,1-0,2$ & 35,5 & 178,4 & $106,9 \mathrm{a}$ \\
\hline $0,2-0,3$ & 36,3 & 44,2 & $40,3 \mathrm{a}$ \\
\hline $0,3-0,4$ & 134,4 & 79,2 & $106,8 \mathrm{a}$ \\
\hline Média & $79,5 \mathrm{~A}$ & $117,1 \mathrm{~A}$ & - \\
\hline$\overline{C V}(\%)$ & \multicolumn{2}{|r|}{89,19} & \\
\hline
\end{tabular}

porosidade total e da macroporosidade, sem aumento da microporosidade.

As alterações impostas pela CA não chegaram a exceder o valor considerado por Reichert et al. (2007, 2009) como crítico ao desenvolvimento de plantas. A redução nos valores de macroporosidade, com a compactação, não foi suficiente para gerar diferenças na condutividade hidráulica do solo ao longo do perfil (Tabela 2). Isto, provavelmente, é decorrente do grande coeficiente de variação observado para essa variável.

Os efeitos da compactação sobre a resistência mecânica do solo à penetração podem ser visualizados na Figura 1. A compactação adicional elevou os valores de resistência à penetração em relação ao $\mathrm{PD}$, nas profundidades de 0,03 a $0,12 \mathrm{~m}$, e não houve diferença significativa abaixo dessa camada, o que indica que ela apresenta a maior concentração das tensões geradas pelo tráfego (Collares et al., 2008; Secco et al., 2009).

$\mathrm{O}$ maior valor de resistência à penetração $(1,5 \mathrm{MPa})$ foi observado a $0,13 \mathrm{~m}$ de profundidade, no tratamento CA. Para o tratamento PD, os valores de resistência à penetração não foram superiores a 1,4 MPa, que ocorreu a aproximadamente $0,20 \mathrm{~m}$ de profundidade, em razão do aumento da densidade do solo, tal como constatado por Genro Junior et al. (2004).

$\mathrm{O}$ esforço de tração exigido pela haste escarificadora (Figura 2) sofreu influência da compactação induzida e apresentou um incremento de $21,64 \%$, em comparação à demanda no solo sob plantio direto. Isso resulta em aumento da demanda de potência, o que, segundo Casão Júnior et al. (1998), é um problema comumente observado em operações de semeadura, pois o trator normalmente não tem reserva de torque suficiente para esse serviço.

A elevação da demanda média de tração de 5,33 $\mathrm{kN}$ (PD) para 6,35 $\mathrm{kN}$ (CA) foi estatisticamente significativa. Rosa (2007) também constatou aumento na exigência de tração de uma haste escarificadora à profundidade de $0,25 \mathrm{~m}$ e com teor de água no solo de $29,9 \mathrm{~kg} \mathrm{~kg}^{-1}$, em consequência do tráfego em Argissolo Vermelho-Amarelo. Esse autor observou que oito passadas de uma pá carregadora $(10 \mathrm{Mg})$, em solo manejado com plantio direto por 13 anos, incrementou em $15,9 \%$ a demanda de tração. Esses valores foram bastante superiores a $23,50 \mathrm{kN}$ e $19,76 \mathrm{kN}$, para CA e PD, respctivamente, observados no presente estudo, possivelmente em razão da maior profundidade de trabalho do escarificador utilizada por Rosa (2007). Entretanto, essa diferença deve-se, principalmente, 

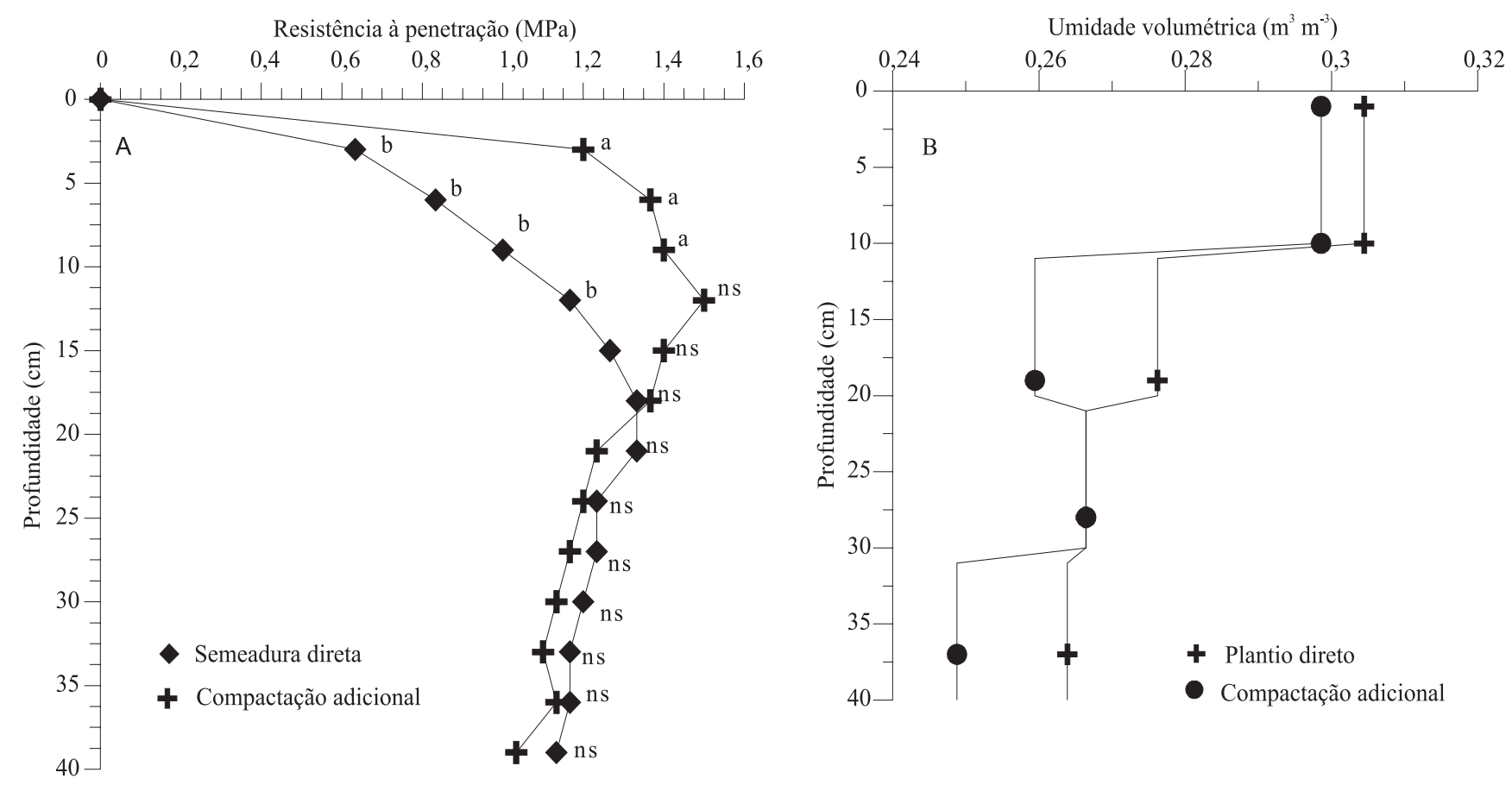

Figura 1. Resistência mecânica à penetração $(\mathrm{A})$ e umidade volumétrica do solo $(\mathrm{B})$ em diferentes profundidades nos diferentes tratamentos. Médias seguidas por letras iguais, em uma mesma profundidade, não diferem pelo teste DMS, a 5\% de probabilidade.

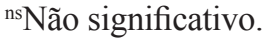

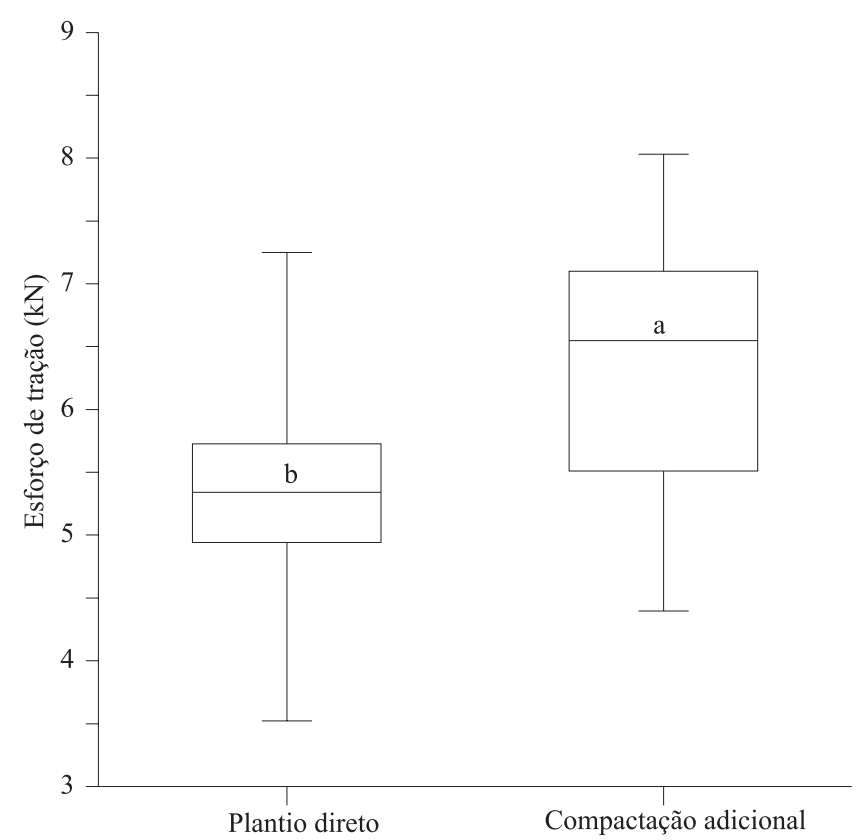

Figura 2. Percentis do esforço de tração exigido pela haste escarificadora, em Argissolo Vermelho-Amarelo submetido a plantio direto com e sem compactação adicional. Médias seguidas por letras iguais não diferem entre si pelo teste DMS, a $5 \%$ de probabilidade. ao elevado estado de compactação do solo naquele estudo, com reflexos sobre a demanda de esforços dos mecanismos rompedores do solo (Bianchini et al., 1999; Conte et al., 2007).

Independentemente da ação da escarificação e da compactação, não foi observada interação entre as profundidades avaliadas e os tratamentos sobre as propriedades físicas do solo abaixo da profundidade de trabalho da haste escarificadora (Tabela 3). Foram observados efeitos dos tratamentos sobre a densidade e a porosidade total do solo, mas não sobre macro e microporosidade. As maiores densidades foram encontradas nos tratamentos que sofreram ação do tráfego (CA e CA escarificado) que, no entanto, apresentaram diferenças significativas apenas em relação ao solo em PD sem escarificação. Esse comportamento também foi observado nos valores médios de porosidade total.

$\mathrm{O}$ efeito da haste escarificadora no tratamento plantio direto aumentou em 5,4\% a densidade do solo e reduziu em 5,5\% a porosidade total (Tabela 3 ). No solo com CA, a escarificação reduziu a densidade $(1,3 \%)$ e a porosidade total $(2 \%)$. No entanto, em 
Tabela 3. Densidade do solo, porosidade total, microporosidade, macroporosidade e condutividade hidráulica do solo saturado abaixo da linha de atuação da haste escarificadora, em Argissolo Vermelho-Amarelo sob plantio direto, com ou sem uso de compactação adicional, e submetido ou não à escarificação ${ }^{(1)}$.

\begin{tabular}{|c|c|c|c|c|c|}
\hline \multirow{2}{*}{$\begin{array}{l}\text { Camada } \\
(\mathrm{m})\end{array}$} & \multicolumn{2}{|c|}{ Plantio Direto } & \multicolumn{2}{|c|}{ Compactação adicional } & \multirow[t]{2}{*}{ Média } \\
\hline & Não escarificado & Escarificado & Não escarificado & Escarificado & \\
\hline & \multicolumn{5}{|c|}{ Densidade do solo $\left(\mathrm{Mg} \mathrm{m}^{-3}\right)$} \\
\hline $0,2-0,3$ & 1,48 & 1,56 & 1,63 & 1,61 & $1,57 \mathrm{a}$ \\
\hline $0,3-0,4$ & 1,46 & 1,54 & 1,56 & 1,55 & $1,53 \mathrm{a}$ \\
\hline Média & $1,47 \mathrm{~B}$ & $1,55 \mathrm{AB}$ & $1,60 \mathrm{~A}$ & $1,58 \mathrm{~A}$ & - \\
\hline \multirow{2}{*}{$\mathrm{CV}(\%)$} & \multicolumn{5}{|c|}{4,84} \\
\hline & \multicolumn{5}{|c|}{ Porosidade total $\left(\mathrm{m}^{3} \mathrm{~m}^{-3}\right)$} \\
\hline $0,2-0,3$ & 0,382 & 0,360 & 0,347 & 0,347 & $0,359 \mathrm{a}$ \\
\hline$\underline{0,3-0,4}$ & 0,383 & 0,363 & 0,369 & 0,356 & $0,368 \mathrm{a}$ \\
\hline Média & $0,382 \mathrm{~A}$ & $0,361 \mathrm{AB}$ & $0,358 \mathrm{~B}$ & $0,351 \mathrm{~B}$ & - \\
\hline \multirow[t]{2}{*}{$\mathrm{CV}(\%)$} & \multicolumn{4}{|c|}{5,29} & \\
\hline & \multicolumn{5}{|c|}{ Microporosidade $\left(\mathrm{m}^{3} \mathrm{~m}^{-3}\right)$} \\
\hline $0,2-0,3$ & 0,289 & 0,257 & 0,276 & 0,270 & $0,273 \mathrm{a}$ \\
\hline$\underline{0,3-0,4}$ & 0,277 & 0,281 & 0,276 & 0,266 & $0,275 \mathrm{a}$ \\
\hline Média & $0,283 \mathrm{~A}$ & $0,269 \mathrm{~A}$ & $0,276 \mathrm{~A}$ & $0,268 \mathrm{~A}$ & - \\
\hline \multirow[t]{2}{*}{$\mathrm{CV}(\%)$} & \multicolumn{4}{|c|}{10,48} & \\
\hline & \multicolumn{5}{|c|}{ Macroporosidade $\left(\mathrm{m}^{3} \mathrm{~m}^{-3}\right)$} \\
\hline $0,2-0,3$ & 0,093 & 0,103 & 0,071 & 0,076 & $0,086 \mathrm{a}$ \\
\hline$\underline{0,3-0,4}$ & 0,106 & 0,082 & 0,093 & 0,089 & $0,093 \mathrm{a}$ \\
\hline Média & $0,099 \mathrm{~A}$ & $0,092 \mathrm{~A}$ & $0,082 \mathrm{~A}$ & $0,083 \mathrm{~A}$ & - \\
\hline \multirow[t]{2}{*}{$\mathrm{CV}(\%)$} & \multicolumn{4}{|c|}{19,61} & \\
\hline & \multicolumn{5}{|c|}{ Condutividade hidráulica de solo saturado $\left(\mathrm{mm} \mathrm{h}^{-1}\right)$} \\
\hline $0,2-0,3$ & 36,3 & 20,8 & 44,2 & 190,2 & $72,9 b$ \\
\hline $0,3-0,4$ & 134,4 & 188,2 & 79,2 & 334,2 & $184,0 \mathrm{a}$ \\
\hline Média & $85,4 \mathrm{~B}$ & $104,5 \mathrm{~B}$ & $61,7 \mathrm{~B}$ & $262,2 \mathrm{~A}$ & - \\
\hline$\overline{\mathrm{CV}(\%)}$ & \multicolumn{4}{|c|}{97,29} & \\
\hline
\end{tabular}

${ }^{(1)}$ Médias seguidas de letras iguais, minúsculas nas colunas e maiúsculas nas linhas, não diferiram entre si pelo teste DMS, a 5\% de probabilidade.

ambos os tratamentos, estas diferenças não foram significativas. Isso mostra que a haste escarificadora não danifica a estrutura física do solo abaixo de sua profundidade de trabalho, e não provoca o pé-de-arado.

A condutividade hidráulica saturada foi maior no tratamento CA escarificado e na camada de 0,30 0,40 m. Nessa camada, também foram observados os menores valores de densidade do solo e maiores valores de porosidade total. Observou-se incremento nos valores de condutividade hidráulica do solo saturado, com a realização da escarificação. Embora a diferença não seja significativa, a escarificação elevou a condutividade hidráulica em $22,4 \%$ no solo sob plantio direto. No caso da compactação adicional (CA), a escarificação elevou a condutividade hidráulica em $325,0 \%$, que foi uma diferença estatisticamente significativa. A escarificação age positivamente em solo francoarenoso e eleva a condutividade hidráulica do solo saturado abaixo da linha de atuação da haste escarificadora.

\section{Conclusões}

1. A intensidade de tráfego tem efeitos negativos sobre as propriedades físico-hídricas do solo, com elevação dos valores de densidade e resistência mecânica à penetração e redução da porosidade total e da macroporosidade.

2. A compactação do solo aumenta a demanda de tração pela haste escarificadora.

3. A escarificação não eleva o estado de compactação do solo abaixo da profundidade de trabalho da haste escarificadora, em solo de textura francoarenosa sob plantio direto.

\section{Referências}

BIANCHINI, A.; SABINO, M.H.C.; BORGES, P.H.M.; SGUAREZZI, J.J. Comportamento operacional de um escarificador de hastes parabólicas em solo de Cerrado. Revista Brasileira de Engenharia Agrícola e Ambiental, v.3, p.395-401, 1999.

CAMARA, R.K.; KLEIN, V.A. Escarificação em plantio direto como técnica de conservação do solo e da água. Revista Brasileira de Ciência do Solo, v.29, p.789-796, 2005. 
CASÃO JÚNIOR, R.; ARAÚJO, A.G. de; RALISCH, R.; SILVA, A.L. da; LADEIRA, A. de S.; SILVA, J.C. da; MACHADO, P.; ROSSETO, R. Avaliação do desempenho da semeadora-adubadora Magnum 2850 em plantio direto no basalto paranaense. Londrina: IAPAR, 1998. 47p. (IAPAR. Circular, 105).

CLAESSEN, M.E.C. (Org.). Manual de métodos de análise de solo. 2.ed. rev. atual. Rio de Janeiro: Embrapa-CNPS, 1997. 212p. (Embrapa-CNPS. Documentos, 1).

COLLARES, G.L.; REINERT, D.J.; REICHERT, J.M.; KAISER, D.R. Compactação de um Latossolo induzida pelo tráfego de máquinas e sua relação com o crescimento e produtividade de feijão e trigo. Revista Brasileira de Ciência do Solo, v.32, p.933-942, 2008.

CONTE, O.; LEVIEN, R.; TREIN, C.R.; CEPIK, C.T.C.; DEBIASI, H. Demanda de tração em haste sulcadora na integração lavoura-pecuária com diferentes pressões de pastejo e sua relação com o estado de compactação do solo. Engenharia Agrícola, v.27, p.220-228, 2007.

FERREIRA, D.F. SISVAR: um programa para análises e ensino de estatística. Revista Symposium, v.6, p.36-41, 2008.

GENRO JUNIOR, S.A.; REINERT, D.J.; REICHERT, J.M. Variabilidade temporal da resistência à penetração de um Latossolo argiloso sob plantio direto com rotação de culturas. Revista Brasileira de Ciência do Solo, v.28, p.477-484, 2004.

GUBIANI, P.I.; REINERT, D.J.; REICHERT, J.M. Método alternativo para a determinação da densidade de partículas do solo: exatidão, precisão e tempo de processamento. Ciência Rural, v.36, p.664-668, 2006.

GUBIANI, P.I.; REINERT, D.J.; REICHERT, J.M.; GELAIN, N.S. Ksat 2008 - programa computacional auxiliar na determinação da condutividade hidráulica do solo saturado pelo método do permeâmetro de carga decrescente. In: REUNIÃO BRASILEIRA DE MANEJO E CONSERVAÇÃO DO SOLO E DA ÁGUA, 17., 2008. Anais. Rio de Janeiro: Sociedade Brasileira de Ciência do Solo, 2008. 1 CD ROM.

HÅKANSSON, I. Machinery-induced compaction of arable soils: incidence, consequences, counter-measures. Uppsala: Swedish University of Agricultural Sciences, 2005. 153p.

HÅKANSSON, I.; MEDVEDEV, V.W. Protection of soils from mechanical overloading by establishing limits for stresses caused by heavy vehicles. Soil and Tillage Research, v.35, p.85-97, 1995.

KLEIN, V.A.; VIEIRA, M.L.; DURIGON, F.F.; MASSING, J.P.; FÁVERO, F. Porosidade de aeração de um Latossolo Vermelho e rendimento de trigo em plantio direto escarificado. Ciência Rural, v.38, p.365-371, 2008.
MORENO, J.A. Clima do Rio Grande do Sul. Porto Alegre: Secretaria da Agricultura, Diretoria de Terras e Colonizações, 1961. 46p.

REICHERT, J.M.; SUZUKI, L.E.A.S.; REINERT, D.J. Compactação do solo em sistemas agropecuários e florestais: identificação, efeitos, limites críticos e mitigação. In: CERETTA, C.A.; SILVA, L.S. da; REICHERT, J.M. (Ed.). Tópicos em ciência do solo. Viçosa: Sociedade Brasileira de Ciência do Solo, 2007. v.5, p.49-134.

REICHERT, J.M.; SUZUKI, L.E.A.S.; REINERT, D.J.; HORN, R.; HÅKANSSON, I. Reference bulk density and critical degree-of-compactness for no-till crop production in subtropical highly weathered soils. Soil and Tillage Research, v.102, p.242-254, 2009.

REINERT, D.J.; ALBUQUERQUE, J.A.; REICHERT, J.M.; AITA, C.; ANDRADA, M.M.C. Limites críticos de densidade do solo para o crescimento de raízes de plantas de cobertura em Argissolo Vermelho. Revista Brasileira de Ciência do Solo, v.32, p.1805-1816, 2008.

ROSA, D.P. da. Comportamento dinâmico e mecânico do solo sob níveis diferenciados de escarificação e compactação. 2007. 122p. Dissertação (Mestrado) - Universidade Federal de Santa Maria, Santa Maria.

ROSA, D.P. da; REICHERT, J.M.; SATTLER, A.; REINERT, D.J.; MENTGES, M.I.; VIEIRA, D.A. Relação entre solo e haste sulcadora de semeadora em Latossolo escarificado em diferentes épocas. Pesquisa Agropecuária Brasileira, v.43, p.395-400, 2008.

SANTOS, H.G. dos; JACOMINE, P.K.T.; ANJOS, L.H.C. dos; OLIVEIRA, V.A. de; OLIVEIRA, J.B. de; COELHO, M.R.; LUMBRERAS, J.F.; CUNHA, T.J.F. (Ed.). Sistema brasileiro de classificação de solos. 2.ed. Rio de Janeiro: Embrapa Solos, 2006. $306 \mathrm{p}$.

SECCO, D.; REINERT, D.J.; REICHERT, J.M.; SILVA, V.R. da. Atributos físicos e rendimento de grãos de trigo, soja e milho em dois Latossolos compactados e escarificados. Ciência Rural, v.39, p.58-64, 2009.

STRECK, C.A.; REINERT, D.J.; REICHERT, J.M.; KAISER, D.R. Modificações em propriedades físicas com a compactação do solo causada pelo tráfego induzido de um trator em plantio direto. Ciência Rural, v.34, p.755-760, 2004.

VEIGA, M. da; HORN, R.; REINERT, D.J.; REICHERT, J.M. Soil compressibility and penetrability of an Oxisol from southern Brazil, as affected by long-term tillage systems. Soil and Tillage Research, v.92, p.104-113, 2007.

Recebido em 3 de janeiro de 2010 e aprovado em 12 de fevereiro de 2010 